\title{
Relationship between sensory attributes and volatile compounds of polish dry-cured loin
}

\author{
Ewa Górska ${ }^{1, *}$, Katarzyna Nowicka', Danuta Jaworska', Wiesław Przybylskii ${ }^{1}$, and Krzysztof Tambor ${ }^{1}$
}

* Corresponding Author: Ewa Górska Tel: +48-660-730-763, Fax: +48-22-59-37-066

E-mail: ewa_gorska1@sggw.pl

1 Department of Food Gastronomy and Food Hygiene, Faculty of Human Nutrition and Consumer Sciences, Warsaw University of Life Sciences, Warsaw 02-776, Poland

Submitted Mar 29, 2016; Revised May 25, 2016; Accepted Jul 13, 2016
Objective: The aim of this work was to determine the relationship between objective sensory descriptors and volatile flavour compound composition of Polish traditional dry-cured loin. Methods: The volatile compounds were investigated by using solid phase microextraction (SPME) and gas chromatography-mass spectrometry (GC-MS). For sensory assessment, the quantitative descriptive analysis (QDA) method was used.

Results: A total of 50 volatile compounds were found and assigned to 17 chemical families. Most of the detected volatile compounds derived from smoking, lipid oxidative reactions and seasoning $(46.8 \%, 21.7 \%$, and $18.9 \%$, respectively). The dominant compounds were: aromatic hydrocarbon (toluene); alkanes (hexane, heptane, and 2,2,4-trimethylpentane); aldehyde (hexanal); alcohol (2-furanmethanol); ketone (3-hydroxy-2-butanone); phenol (guaiacol); and terpenes (eucalyptol, cymene, $\gamma$-terpinen, and limonene). Correlation analysis showed that some compounds derived from smoking were positively correlated with the intensity of cured meat odour and flavour and negatively with the intensity of dried meat odour and flavour, while terpenes were strongly correlated with odour and flavour of added spices.

Conclusion: The analysed dry-cured loins were characterized by specific and unique sensory profile. Odour and flavour of studied loins was mainly determined by volatile compounds originating from smoking, seasoning and lipid oxidation. Obtained results suggest that smoking process is a crucial stage during Polish traditional dry-cured loins production.

Keywords: Dry-cured Loin; Sensory Quality; Volatile Compounds

\section{INTRODUCTION}

Traditional food is an important element of the European cultural heritage. Foodstuff prepared with traditional methods, using old recipes, cultivated by local communities is considered to be tasty, healthy and natural. Production and sale of traditional food products provide a decisive economic input to many regions of the European Union [1]. Also in Poland a growing interest in traditional food has been observed in recent years. Smoked meats and sausages are most frequently purchased by Polish consumers, however a growing number of producers often offer more durable products with unique and high quality, classified as luxury products [2]. Such products are dry-cured meat products, which are manufactured in many countries, nevertheless the main production is located in the Mediterranean area.

Sensory quality of well-known Spanish, Italian and French dry-cured meat products varies depending on the pig breed, rearing system, carcass weight, type of cut and particular processing conditions $[3,4]$. However, the production of dry-cured loins and hams in these countries is similar and usually consists of four stages - dry salting with salt and other ingredients, washing, postsalting for salt equalization and then drying for 3 to 6 months, nevertheless most of them are cured for 9 to 12 months or even 24 months. During this period humidity and temperature are controlled to reduce the risk of bacterial spoilage [5]. In Poland, traditional manufacturing 
technology of dry-cured meat products is based on the dry salting with salt, spices and sometimes starter cultures, and two-step maturation (under a constant temperature and low humidity conditions) for 6 to 8 months. Obtained products can also undergo a cold smoking process [2]. Often the raw material for this production originates from native breeds. There are three native breeds of pigs in Poland - Zlotnicka White, Zlotnicka Spotted, and Pulawska, of which Zlotnicka White is the most popular [6].

Aroma and flavour are key attributes that impact the overall acceptance of dry-cured loins and are markedly affected by raw material, production process and aging time. These attributes can be determined by sensory descriptive analysis and the composition of volatile compounds $[7,8]$. In dry-cured meat products, during the ripening process, complex chemical and biochemical changes in the main components of raw meat (proteins and lipids) lead to the generation of flavour precursors such as peptides, free amino acids and free fatty acids, which are transformed to volatiles. Except volatile compounds derived from lipolysis and proteolysis aroma can be formed from spices added in the production process $[4,9,10]$. Several studies have been conducted to identify and quantify the volatile compounds in various kinds of dry-cured loins and hams, including Iberian [11,12], Parma [13], Bayonne [14], Istrian [4], and American [8]. Nevertheless, little information is available for dry-cured loins produced in Poland.

The aim of this work was to carry out a reliable identification of the volatile compounds composition in a traditional dry-cured loin made in Poland using solid phase microextraction (SPME) and gas chromatography-mass spectrometry (GC-MS). Another purpose was to determine the relationship between objective sensory descriptors and volatile flavour compound composition of studied dry-cured loins.

\section{MATERIAL AND METHODS}

\section{Samples}

The study was carried out with 15 dry-cured loins made from meat of Zlotnicka White pigs purchased from three different manufacturers ( 5 dry-cured loins from each manufacturer) and 6 dry-cured loins made from meat of crossbreed of Polish Large White and Polish Landrace pigs purchased from one manufacturer. Dry-cured loins were processed by local manufacturers using the caudal half of the Longissimus dorsi muscle of all animals. Loins were seasoned with the mixture of salt, nitrates and spices (400 g per kg) and kept at $4^{\circ} \mathrm{C}$ and relative humidity of $75 \%$ to $80 \%$ for 2 to 4 weeks. Afterwards, loins were washed with cold water to remove the excessive salt. All 15 dry-cured loins obtained from the meat of Zlotnicka White pigs underwent a cold smoking process $\left(16^{\circ} \mathrm{C}\right.$ to $22^{\circ} \mathrm{C}$ ) twice within 14 days (2 days of smoking and 5 days of aging), while loins made from the meat of the crossbreed of Polish Large White and Polish Landrace pigs did not undergo this process. Eventually, all loins were hung up and ripened under a constant temperature (about $10^{\circ} \mathrm{C}$ to $15^{\circ} \mathrm{C}$ ) and relatively low humidity condition (65\% to $75 \%$ ) for 2 to 3 months.

Once the ripening process was finished, dry-cured loins were vacuum packaged to avoid an excessive dehydration of the product until evaluation. All dry-cured loins were purchased whole. For sensory evaluation the center part of loins (amount of 500 to $600 \mathrm{~g}$ ) were used. Remaining pieces of dry-cured loins were cut in pieces of 20 to $30 \mathrm{~g}$ for further analysis, packed in closed Ziploc bags and frozen at $-80^{\circ} \mathrm{C}$. The samples were stored for up to one month.

\section{Sensory analysis}

The sensory analysis was conducted immediately after opening the packages. For sensory assessment, the quantitative descriptive analysis (QDA) method [15] was used and an unstructured, linear graphical scale $(100 \mathrm{~mm})$ was converted to numerical values $(0$ to 10 conventional units). Sensory quality was characterized on the basis of 16 sensory attributes, grouped in odour, flavour and overall quality. Descriptors were chosen and defined during the panel discussion and then verified in the preliminary session. The marks of anchors of the tested attributes were as follows for most of them: no intensity - high intensity and overall quality (very low to very high).

The trained 10-person assessing panel [16] was experienced (4 to 12 years of sensory evaluation practice), with good command of sensory methodology and familiarity with the sensory quality of meat and meat products. The analytical panel made each evaluation in duplicate (two sessions) therefore each mean result was based on 20 individual measurements. Between the subsequent evaluations, the assessors received hot tea without sugar to neutralize the taste.

The samples were prepared by placing size comparable, $5 \mathrm{~mm}$ thick slices (amount 25 to $30 \mathrm{~g}$ ) in covered, odourless, single-use plastic boxes with lids (volume $150 \mathrm{~mL}$ ). The slices were obtained using a commercial slicing machine (Zelmer 294.5 NP, Rzeszow, Poland). The assessment was performed in special odourless laboratory with daylight and limited noise. The condition mode was determined in accordance with Meilgaard et al [17].

\section{Analysis of volatile compounds}

The analysis of volatile compounds was performed according to the methodology presented by Muriel et al [9] with modifications. Volatile compounds were extracted by SPME (Supelco, Bellefonte, PA, USA) and subsequently analysed by gas chromatography coupled with mass spectrometry (GC-MS) (Agilent Technologies, Palo Alto, CA, USA). To extract volatile compounds from the headspace polydimethylsiloxane/divinylbenzene absorption fiber (PDMS/DVB, $65 \mu \mathrm{m}$ thickness) was used. The fiber was preconditioned at $250^{\circ} \mathrm{C}$ for $60 \mathrm{~min}$ in the GC injector port, according to supplier's instructions.

Approximately $5 \mathrm{~g}$ of homogenized sample (Bosch MSM 67160, Gerlinger, Germany) was placed in a $20 \mathrm{~mL}$ vial, closed with 
silicone-teflon sealing cap and heated to $37^{\circ} \mathrm{C}$ for $1 \mathrm{~h}$ in order to stabilize concentrations of volatile compounds in a vial. Afterwards, SPME fiber was introduced to sample headspace for a period of $45 \mathrm{~min}$. Subsequently, the fiber was quickly transferred from the vial to the GC injector working in "splitless" mode and set to $250^{\circ} \mathrm{C}$, in order to desorb extracted volatiles to $\mathrm{GC}$ system.

Chromatographic separation was performed using GC Agilent 6890 (Agilent Technologies, Palo Alto, CA, USA), coupled with quadruple MS Agilent 5795 (Agilent Technologies, USA). A 5\%-diphenyl-95\%-polydimethylsiloxane capillary column (DB$5 \mathrm{MS}, 30 \mathrm{~m} \times 0.25 \mathrm{~mm} \times 0.25 \mu \mathrm{m}$ ) was used with helium as a carrier gas at a flow rate of $0.9 \mathrm{~mL} / \mathrm{min}$. The $\mathrm{GC}$ oven was programmed as follows: initial temperature of $38^{\circ} \mathrm{C}$ held for 10 minutes, then increased to $200^{\circ} \mathrm{C}$ at a rate of $4^{\circ} \mathrm{C} / \mathrm{min}$ and held for 2 minutes, then increased to $250^{\circ} \mathrm{C}$ at a rate of $20^{\circ} \mathrm{C} / \mathrm{min}$ and final temperature $\left(250^{\circ} \mathrm{C}\right)$ was held for 7 minutes.

Mass spectra were obtained in Electron Ionization (EI) mode (Agilent Technologies, USA) at $70 \mathrm{eV}$ by scanning range of 20 to $350 \mathrm{~m} / \mathrm{z}$ (a.m.u). Temperatures of ion source and mass analyzer were $230^{\circ} \mathrm{C}$ and $150^{\circ} \mathrm{C}$, respectively. Spectra were subsequently analyzed with Enhanced ChemStation Data Analysis program using NIST 08 (US National Institute of Standards and Technology) and Wiley 8th Ed. mass spectra databases. Identification was made on the basis of mass spectra comparison of $90 \%$ minimum accuracy and then confirmed by linear retention indices (LRI) and by using pure compound's standards for selected volatiles. In order to calibrate LRI, C8-C20 alkanes mixture (Fluka, Buchs, Switzerland) and pure standards of hexane and heptane (SigmaAldrich, St. Louis, MO, USA) were analyzed. As a base of retention index data NIST 08 Mass spectra database was used. Volatiles quantities were expressed as percentage of total identified signal.

\section{Statistical analysis}

The results were elaborated using STATISTICA version 10 software (StatSoft, Inc. 2011) and Microsoft Excel 2007 program. Between examined traits simple Pearson correlation coefficients were calculated. The results for the sensory evaluation were elaborated by principal component analysis (PCA). Based on the results of this analysis 3 groups of samples varying in sensory quality and volatile compounds composition have been identified. These results have been developed using one-way analysis of variance. The significance of differences between means was calculated on the basis of the least significant differences test. The impact of the sensory session was insignificant for most evaluated attributes, which positively verifies the experience of the panel and assessments conditions. The obtained results are presented as mean value with standard deviation.

\section{RESULTS AND DISCUSSION}

\section{Sensory evaluation}

The obtained results indicated that all the dry-cured loins studied were characterized by relatively high overall quality. A high intensity of the odour and flavour of smoked meat and salty taste was stated (Table 1). In opposite a low intensity of the sweet taste, sour odour and flavour, "other" odour and flavour was noted. These discriminants (except for sweet taste) were characterized by high variability similar to the intensity of odour and flavour of seasoning, spicy and herbal. Differences in sensory quality of studied dry-cured loins may be the result of diversified raw material and slightly different production technology. Appearance and texture attributes of dry-cured meat products mainly depend on the genetic features of the pig breed, while flavour and odour attributes are markedly affected by processing techniques and aging time $[12,18,19]$.

The results for the sensory evaluation were elaborated by PCA. Based on the results of this analysis 3 groups of samples varying in sensory quality have been identified. The results of PCA showed that $57.07 \%$ of total variation in the data could be explained by two principal components (Table 2). The PC1 dimension, that explained $36.91 \%$ of the variance, was strongly and positively associated with seasoning, spicy and herbal odour and flavour, sour odour and flavour, cured meat odour and "other" flavour, and negatively with dried meat odour and flavour, salty taste and smoked meat flavour. The PC2 dimension, which explained an additional $20.16 \%$ of the variance, was positively correlated with smoked meat odour and flavour, cured meat odour and flavour and overall quality, and negatively with "other" odour and flavour (Table 2).

The distribution of all analyzed samples in the area created by two principal components (based on the sensory attributes) is shown in Figure 1. Samples were grouped into three clusters with their own, unique sensory profile. The I group had the highest intensity of sour as well as seasoning, spicy and herbal odour and

Table 1. Characteristics of sensory quality of dry-cured loins based on quantitative descriptive analysis method $(n=21)$

\begin{tabular}{lccc}
\hline $\begin{array}{l}\text { Intensity of studied attributes } \\
\text { [0 to 10 c.u.] }\end{array}$ & $\begin{array}{c}\text { Mean } \\
\text { value }\end{array}$ & $\begin{array}{c}\text { Standard } \\
\text { deviation }\end{array}$ & $\begin{array}{c}\text { Coefficient of } \\
\text { variation }\end{array}$ \\
\hline Cured meat odour & 5.74 & 1.62 & 28.15 \\
Smoked meat odour & 6.25 & 1.30 & 20.83 \\
Dried meat odour & 5.28 & 1.39 & 26.36 \\
Seasoning, spicy and herbal odour & 3.36 & 1.90 & 56.58 \\
Fatty odour & 2.32 & 0.42 & 18.20 \\
Sour odour & 1.92 & 0.75 & 38.89 \\
"Other" odour & 1.68 & 0.79 & 46.83 \\
Cured meat flavour & 5.85 & 1.56 & 26.61 \\
Smoked meat flavour & 6.18 & 1.20 & 19.47 \\
Dried meat flavour & 5.16 & 1.40 & 27.12 \\
Seasoning, spicy and herbal flavour & 3.14 & 1.72 & 54.60 \\
Salty taste & 6.04 & 1.42 & 23.46 \\
Sweet taste & 1.55 & 0.39 & 25.41 \\
Sour flavour & 2.15 & 1.04 & 48.39 \\
"Other" flavour & 1.76 & 1.08 & 61.41 \\
Overall quality & 6.43 & 0.69 & 10.82 \\
\hline
\end{tabular}

c.u.- conventional unites. 
Table 2. The load factors of main two principal components of measured sensory attributes

\begin{tabular}{lcc}
\hline & PC1 & PC2 \\
\hline Intensity of cured meat odour & 0.52 & 0.8 \\
Intensity of smoked meat odour & -0.20 & 0.83 \\
Intensity of dried meat odour & -0.81 & 0.11 \\
Intensity of seasoning, spicy and herbal odour & 0.91 & -0.04 \\
Intensity of fatty odour & -0.03 & 0.23 \\
Intensity of sour odour & 0.81 & -0.01 \\
Intensity of "other" odour & -0.07 & -0.89 \\
Intensity of cured meat flavou & 0.47 & 0.77 \\
Intensity of smoked meat flavour & -0.63 & 0.66 \\
Intensity of dried meat flavour & -0.84 & 0.07 \\
Intensity of seasoning, spicy and herbal flavour & 0.90 & -0.15 \\
Intensity of salty taste & -0.66 & -0.00 \\
Intensity of sweet taste & 0.19 & -0.01 \\
Intensity of sour flavour & 0.75 & -0.10 \\
Intensity of "other" flavour & 0.64 & -0.52 \\
Overall quality & 0.05 & 0.60 \\
\% of variance & 36.91 & 20.16 \\
\hline
\end{tabular}

$\mathrm{PC1}$, principal component 1; $\mathrm{PC2}$, principal component 2 .

flavour or "other" flavour, but the lowest intensity of dried meat odour and flavour or smoked meat flavour (Figure 2). The II group was characterized by the lowest intensity of cured meat odour and flavour, but the highest intensity of "other" odour and salty taste (which was similar as in III group). According to Yim

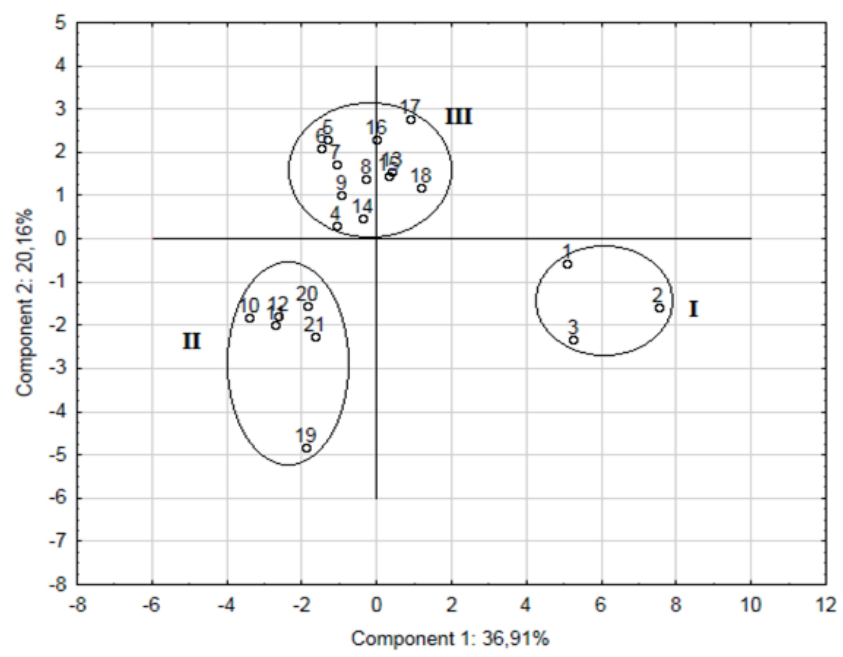

Figure 1. The results of principal component analysis (PCA) - distribution of all analyzed samples presented in the first two principal components PC1 and PC2. I, II, III, groups of samples varying in sensory quality.

et al [20], salty taste is not only determined by the addition of salt, but may be influenced by other compounds like nucleotides and amino acids or a low content of intramuscular fat. The III group was only distinguished by the highest intensity of smoked meat odour (Figure 2).

Overall quality has not differed significantly between separated

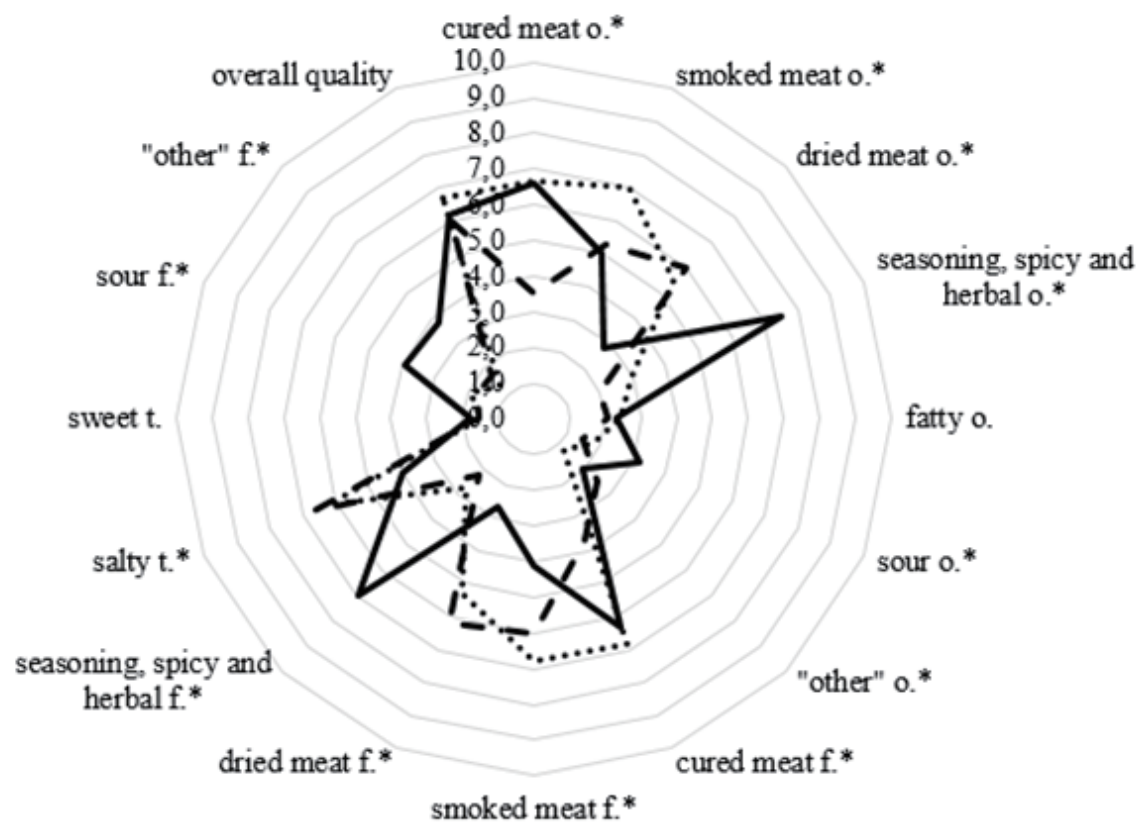

Figure 2. Sensory profile (quantitative descriptive analysis [QDA] method) of three groups of dry-cured loins obtained according to principal component analysis (PCA). * Values are significantly different $(p<0.05)$. 
groups, however it has higher scores in III group and lower in II group. This may suggest that panelists estimated higher drycured loins with distinct smoked and cured meat odour and flavour. Similar findings have been observed among consumers of American dry-cured ham [8]. These results are in accordance with the ones reported by Fortin et al [21] in which juiciness, tenderness, flavour and absence of off-flavours were the most important attributes comprising the sensory experience during meat consumption.

\section{Volatile profile of dry cured loin}

A total of 50 volatile compounds were detected and identified

Table 3. Contents of volatile compounds quantified in dry-cured loins (percentage of the total area)

\begin{tabular}{|c|c|c|c|c|c|c|c|c|}
\hline \multirow{2}{*}{ No. } & \multirow{2}{*}{ RT } & \multirow{2}{*}{ Compound name } & \multirow{2}{*}{ ID } & \multicolumn{3}{|c|}{ Group } & \multirow{2}{*}{ Family } & \multirow{2}{*}{ Source of volatile compounds } \\
\hline & & & & 1 & II & III & & \\
\hline 1 & 4.668 & Pyridine & $M S+L R I$ & 0.69 & 0.02 & 0.36 & Pyridines & Smoke \\
\hline 2 & 5.38 & Methylbenzene (Toluene) & $M S+L R I$ & 7.53 & 30.25 & 36.58 & Aromatic hydrocarbones & \\
\hline 3 & 8.449 & Furfural & $M S+L R I+S T$ & 1.36 & ND & 1.00 & Aldehydes & \\
\hline 4 & 8.89 & 2-methyl-cyclopentanone & $M S+L R I$ & ND & ND & 0.07 & Cyclopentanones & \\
\hline 5 & 10.353 & Ethylbenzene & $M S+L R I$ & ND & 0.07 & ND & Aromatic hydrocarbons & \\
\hline 6 & 10.703 & 2-Furanmethanol & $M S+L R I+S T$ & 7.41 & ND & 0.87 & Alcohols & \\
\hline 7 & 13.527 & 2-methyl-2-cyclopenten-1-one & $M S+L R I$ & 1.20 & 0.02 & 0.95 & Cyclopentenones & \\
\hline 8 & 17.022 & 3-methyl-2-cyclopenten-1-one & $M S+L R I$ & 1.54 & ND & 1.58 & Cyclopentenones & \\
\hline 9 & 20.807 & 2,3-dimethyl-2-cyclopenten-1-one & $M S+L R I$ & 1.11 & 0.01 & 0.98 & Cyclopentenones & \\
\hline 10 & 22.79 & 3-methylphenol & $M S+L R I$ & 0.91 & ND & 1.72 & Phenols & \\
\hline 11 & 23.201 & guaiacol & $M S+L R I$ & 4.91 & ND & 3.28 & Phenols & \\
\hline 12 & 27.363 & 2-methoxy-4-methyl-phenol & $M S+L R I$ & 2.02 & ND & 1.50 & Phenols & \\
\hline 13 & 30.496 & 4-ethylguaiacol & $M S+L R I$ & 0.67 & ND & 0.59 & Phenols & \\
\hline 14 & 2.266 & Hexane & $M S+L R I+S T$ & 2.10 & 7.71 & 5.81 & Alkanes & Lipid oxidation \\
\hline 15 & 3.491 & Heptane & $M S+L R I+S T$ & 2.79 & 10.94 & 7.33 & Alkanes & \\
\hline 16 & 6.639 & Hexanal & $M S+L R I+S T$ & 0.17 & 8.84 & 1.32 & Aldehydes & \\
\hline 17 & 12.773 & 2-Heptanone & $M S+L R I$ & 0.03 & 0.35 & 0.09 & Ketones & \\
\hline 18 & 19.224 & Octanal & $M S+L R I+S T$ & 0.12 & 0.21 & 0.31 & Aldehydes & \\
\hline 19 & 23.872 & Nonanal & $M S+L R I+S T$ & 0.53 & 0.46 & 0.93 & Aldehydes & \\
\hline 20 & 27.661 & Dodecane & $M S+L R I$ & 0.11 & 0.27 & 0.15 & Aliphatic hydrocarbons & \\
\hline 21 & 27.876 & Decanal & $M S+L R I$ & 0.04 & 0.04 & 0.05 & Aldheydes & \\
\hline 22 & 1.686 & Ethanol & $\mathrm{MS}+\mathrm{ST}$ & 1.06 & 0.50 & 0.69 & Alcohols & Carbohydrate fermentation \\
\hline 23 & 3.83 & 3-hydroxy-2-butanone & $M S+L R I$ & 0.16 & 9.13 & 0.22 & Ketones & \\
\hline 24 & 6.059 & 2,3-Butanediol & $M S+L R I$ & 0.22 & 1.80 & 0.15 & Glycol & \\
\hline 25 & 4.038 & Butanoic acid, methyl ester & $M S+L R I$ & 0.05 & 0.11 & 0.13 & Esters & Microorganisms esterification \\
\hline 26 & 11.981 & 3-methyl-butanoic acid & $M S+L R I$ & ND & 0.24 & ND & Acids & \\
\hline 27 & 14.865 & Thujene & $M S+L R I$ & 0.55 & 0.01 & 0.05 & Terpenes & Spices \\
\hline 28 & 15.16 & a-pinene & $M S+L R I$ & 1.29 & 0.07 & 0.31 & Terpenes & \\
\hline 29 & 15.955 & Camphene & $M S+L R I$ & 0.41 & ND & 0.04 & Terpenes & \\
\hline 30 & 17.497 & Sabinen & $M S+L R I$ & 0.96 & 0.13 & 0.44 & Terpenes & \\
\hline 31 & 19.374 & 4-Carene & $M S+L R I$ & 0.20 & 0.87 & 0.78 & Terpenes & \\
\hline 32 & 19.74 & $a$-Terpinen & $M S+L R I$ & 0.86 & ND & 0.03 & Terpenes & \\
\hline 33 & 20.189 & Cymene & $M S+L R I$ & 6.64 & 0.14 & 0.23 & Terpenes & \\
\hline 34 & 20.351 & Limonene & $M S+L R I+S T$ & 1.30 & 0.71 & 1.05 & Terpenes & \\
\hline 35 & 20.498 & Eucalyptol & $M S+L R I$ & 14.90 & ND & ND & Terpenes & \\
\hline 36 & 21.814 & $\gamma$-Terpinen & $M S+L R I$ & 3.13 & ND & ND & Terpenes & \\
\hline 37 & 22.149 & trans-4-Thujanol & $M S+L R I$ & 0.36 & ND & 0.01 & Terpenes & \\
\hline 38 & 23.521 & cis-4-Thujanol & $M S+L R I$ & 0.67 & ND & ND & Terpenes & \\
\hline 39 & 23.71 & Linalool & $M S+L R I$ & 1.63 & ND & 0.17 & Terpenes & \\
\hline 40 & 25.372 & Camphor & $M S+L R I$ & 1.88 & 0.01 & ND & Terpenoids & \\
\hline 41 & 26.255 & Borneol & $M S+L R I$ & 0.65 & ND & 0.08 & Terpenes & \\
\hline 42 & 26.726 & 4-Terpineol & $M S+L R I$ & 0.89 & 0.02 & 0.17 & Cycloalkanes & \\
\hline 43 & 31.005 & Tymol & $M S+L R I$ & 0.88 & ND & ND & Phenols (derivative) & \\
\hline 44 & 31.702 & 4-Vinylguaiacol & $M S+L R I$ & 0.17 & ND & 0.06 & Phenols & \\
\hline 45 & 33.191 & Eugenol & $M S+L R I$ & 0.31 & ND & 0.07 & Terpenes & \\
\hline 46 & 35.242 & Caryophyllene & $M S+L R I$ & 0.24 & 0.21 & 0.45 & Sesquiterpenes & \\
\hline 47 & 3.269 & 2,2,4-trimethylpentane & $M S+L R I$ & 0.85 & 7.50 & 3.64 & Alkanes & Others \\
\hline 48 & 13.968 & 1-(2-furanyl)-Ethanone & $M S+L R I$ & 0.04 & 0.01 & 0.24 & Ketones & \\
\hline 49 & 14.138 & Butyrolactone & $M S+L R I+S T$ & 0.79 & 0.01 & 0.73 & Lactones & \\
\hline 50 & 17.9 & 3-methyl-2(5H)-Furanone & $M S+L R I$ & 0.60 & ND & 0.48 & Lactones & \\
\hline
\end{tabular}

RT, retention time; ID, method of identification; MS, identification based on MS databases; LRI, identification based on linear retention index; ST, identification based on comparison of spectra and retention time with commercial standards; ND, not detected. 
in the headspace of dry-cured loins using SPME coupled to GC/ MS (Table 3). Identified compounds were assigned to 17 chemical families: acids, alkanes, alcohols, aldehydes, aliphatic, and aromatic hydrocarbons, cycloalkanes, cyclopentanones, cyclopentenones, esters, glycol, ketones, lactones, pyridines, phenols, terpenes, and terpenoids. These groups of volatile compounds mostly agree with the ones reported by different authors for dry-cured loin $[12,22]$ and dry-cured ham $[4,7,14]$. The predominant volatile compound in studied loins was methylbenzene, followed by heptane, hexane, hexanal, eucalyptol and 3-hydroxy-2-butanone (Table 3).

It is essential to identify the origin of the volatile compounds to understand the formation of flavour in dry-cured loins. As reported in case of the same or similar type of meat product, the volatile compounds composition might be due to seasoning, smoking or the reactions between lipids, protein and carbohydrates caused by microbial or endogenous enzymes $[11,23]$. In the studied loins most of the detected volatile compounds derived from smoking, lipid oxidative reactions and seasoning (46.8\%, $21.7 \%$, and $18.9 \%$, respectively).

The volatiles originating from smoking were alcohols, aldehydes, aromatic hydrocarbons, cyclopentanones, cyclopentenones, phenols and pyridines, all of which are characteristic compounds of wood smoke [24]. Phenolic compounds with heavy, pungent, burnt, cresolic, smoky notes and the low sensory threshold values were essential contributors to the flavour of the studied dry-cured loins. Moreover, these compounds had antimicrobial and antioxidant activity, which significantly increases sustainability of smoked products [23]. The predominant volatile compound originating from smoking was methylbenzene (Table 3). However, Théron et al [14] reported that this aromatic hydrocarbon may be created by the oxidation of lipids, the catabolism of phenylalanine or may be just an environmental contaminant. Toluene was the component with the highest area percentage in II and III group, while in I group components with the highest area percentage were toluene and 2-furanmethanol (Table 3). The 2 -furanmethanol, which gives burnt meat and vitamin-like odours, has several suggested formation pathways such as thermal degradation during smoking, the Maillard reaction or the deamination and dehydration of Amadori products during heating [8].

Considering the class of volatile compounds derived from lipid oxidation the most abundant were hydrocarbons - heptane and hexane - although due to their relatively high odour threshold values they probably did not have a significant impact on the final aroma of the studied loins [24]. Straight-chain aliphatic aldehydes are typical products of lipid oxidation with very low odour thresholds. They are responsible for giving fat odour to a product. The principal component in this group was hexanal. High concentration of this compound was also detected in dry-cured ham, fermented sausages and cecinas, which were salted and occasionally smoked and dried meats $[4,24,25]$. Hexanal was probably derived from oxidation of unsaturated fatty acids, such as linoleic and archidonic acid [4,7]. The aroma of hexanal has been described as green, grassy, fatty, rancid, strong, unpleasant, hot and nauseating. Other saturated aliphatic aldehydes give characteristic odours. Octanal gives meat-like, fresh, green, citrus, herbal, and floral odours. Nonanal gives odours described as rancid, fatty, soap, and plastic. While the aroma of decanal has been determined as roasty, sweet, fruity, citrus, waxy, floral, and penetrating $[10,25$, 26]. Methylketone (2-heptanone) is normally responsible for the aroma of "blue cheese" $[7,10]$. In regular dry-cured products, where the microbial population is relatively low, this compound is formed by a chemical process. Though an abnormally high concentration of this volatile compound is an indicator of low quality meat products, it can also be formed by microorganisms [13].

Another, quite numerous group of volatile compounds identified in the studied dry-cured loins, was terpens, phenols and their derivatives originating from spices. Though some terpens have been found in meat as a result of their presence in animal feedstuffs [4]. The dominant compound was eucalyptol, however it was found only in samples from I group (Table 3). Eucalyptol may originate from bay leaves, rosemary or basil [27]. Other terpens found in high concentration were cymene, limonene, $\gamma$-terpinen, $\alpha$-pinene, sabinene and linalool, which may have been derived from the added black pepper, rosemary and laurel [4]. High concentrations of 4-carene and camphor probably resulted from the use of rosemary, whereas thymol, which was found only in dry-cured loins from I group, was most likely derived from marjoram or thyme [27]. Characteristic odours given by terpens are well established. The aroma of limonene has been described as fresh, citric and wood, while a-pinene gives sharp, pine and peppery notes $[10,26,28]$. The variability observed among the groups in the content of terpenes showed that different amount of spices had been added during the production of the different dry-cured loins.

Dry-cured loins belonging to II group showed the highest concentrations of volatile compounds from fermentation of carbohydrates with 3-hydroxy-2-butanone being the most abundant (Table 3). That compound imparts butter, soft and cheese odour and due to low sensory threshold is of great importance to the final aroma $[24,28]$. Presence of 3-hydroxy-2-butanone was reported in other dry-cured loins [11,12,22], dry-cured hams [13], fermented sausages [28] and cecinas [24].

A higher concentration of fermentation compounds in drycured loins from II group indicates a higher metabolic activity of the microbiota in these samples, which is reflected in the amount of volatile compounds derived from microorganisms esterification. The dominant compound (3-methyl-butanoic acid) could be generated from leucine by the functions of Staphylococcus xylosus, Staphylococcus carnosus, or fungal protease EPg222 [29]. Characteristic, unpleasant aroma of 3-methyl-butanoic acid described as cheese, feet and dirty socks may contribute to lower overall quality of loins from II group. According to Montel et al [30], the 
relative input of microbial flora on volatile compounds depends on the number and identity of microorganisms and their metabolic activities. These metabolic activities depend on, inter alia, meat composition, added ingredients and technological variables, such as temperature, $\mathrm{pH}$, gaseous environment or extent of drying. In this work, due to long drying time and higher manufacturing temperatures, microbial activity was considered as a minor factor in the formation of volatile compounds.

\section{Relationship between sensory attributes and volatile compounds}

The specific sensory profile of previously selected groups was reflected in their volatile profile. Odour and flavour of dry-cured loins in the I group were mainly determined by volatile compounds originating from seasoning and smoking (49.3\% and $38.1 \%$, respectively), whereas by compounds derived from lipid oxidation (7.6\%) and carbohydrate fermentation (1.9\%) they were determined to a small extent.

In creating the final aroma of loins in II group the majority was compounds derived from lipid oxidation (35.7\%). The content of compounds originating from carbohydrate fermentation was the highest when compared to other groups and accounted for $14.2 \%$ of the total volatile content. Compounds from unknown sources, particularly 2,2,4-trimethylpentane, were the most abundant among loins in this group, which may correspond to their very high intensity of "other" odour. We assumed that high content of toluene in this group might have derived from lipid oxidation, the catabolism of phenylalanine or the environmental contamination, as loins from this group had not undergone a smoking process [14].

Smoked-derived compounds dominated in the headspace of dry-cured loins from III group (65.4\% of total area percentage). Those loins have certainly undergone an intense smoking process. Lipid oxidation was also an important pathway of volatile generation in the group of dry-cured loins.

Correlation analysis showed that some compounds derived from smoking (especially, pyridine, furfural, 2-methyl-2-cyclopenten-1-one, 2,3-dimethyl-2-cyclopenten-1-one, and guaiacol) were positively correlated with the intensity of cured meat odour and flavour and negatively with the intensity of dried meat odour and flavour, while 2,2,4-trimethylpentane had a positive effect on the intensity of dried meat odour and flavour. Seasoning, spicy and herbal odour and flavour as well as sour odour and flavour were positively correlated with the presence of terpenes, which originate from spices added in salting phase. Similar findings have been reported by Marušić et al [4].

In conclusion, based on the results of this study, it can be stated that dominant compounds in dry-cured loins were: aromatic hydrocarbon (toluene); alkanes (hexane, heptane, and 2,2,4-trimethylpentane); aldehyde (hexanal); alcohol (2-furanmethanol); ketone (3-hydroxy-2-butanone); phenol (guaiacol); and terpenes (eucalyptol, cymene, $\gamma$-terpinen, and limonene). The analysed products were characterized by specific and unique sensory profile and on the basis of Principal Component Analysis were grouped into three different quality clusters. Odour and flavour of drycured loins in the I group was mainly determined by volatile compounds originating from seasoning and smoking, in II group the majority were compounds derived from lipid oxidation, while in III group dominated smoked-derived compounds. Obtained results suggest that smoking process is a crucial stage during Polish traditional dry-cured loins production.

\section{CONFLICT OF INTEREST}

We certify that there is no conflict of interest with any financial organization regarding the material discussed in the manuscript.

\section{REFERENCES}

1.Guerrero L, Claret A, Verbeke W et al. Perception of traditional food products in six European regions using free word association. Food Qual Prefer 2010;21:225-33.

2.Comparison of European \& American Systems of Production and Consumption of Dry-Cured Hams [Internet]. Ockerman HW, Basu L, Crespo FL, Céspedes Sánchez FJ. National Pork Board, American Meat Science Association Fact Sheet; 2010 [cited 2016 Jul 4]. Available from: http://articles.extension.org/pages/27342/ comparison-of-european-american-systems-of-production-andconsumption-of-dry-cured-hams\#top

3. Olkiewicz M, Moch P, Makala H. Characteristics of hams ripening in raw state produced from raw material coming from selected primitive Polish races. Rocz Inst Przem Mięsn Tłuszcz 2006;44:141-9.

4.Marušić N, Petrović M, Vidaček S, Petrak T, Medić H. Characterization of traditional Istrian dry-cured ham by means of physical and chemical analyses and volatile compounds. Meat Sci 2011;88:786-90.

5.Flores J, Toldrá F. Curing: Processes and applications. In: Robinson R, Sadler M, Fullerlove G, Macrae R, editors. Encyclopedia of food science, food technology and nutrition. London: Academic Press; 1993. p. 1277-82.

6.Szulc K, Skrzypczak E. Meat quality of polish native pigs. Wiad Zoot 2015;53:48-57.

7.Sánchez-Peña CM, Luna G, García-González DJ, Aparicio R. Characterization of French and Spanish dry-cured hams: influence of the volatiles from the muscles and the subcutaneous fat quantified by SPME-GC. Meat Sci 2005;69:635-45.

8.Pham AJ, Schilling MW, Mikel WB, et al. Relationships between sensory descriptors, consumer acceptability and volatile flavor compounds of American dry-cured ham. Meat Sci 2008;80:728-37.

9.Muriel E, Antequera T, Petrón MJ, Andrés AI, Ruiz J. Volatile compounds in Iberian dry-cured loin. Meat Sci 2004;68:391-400.

10. Luna G, Aparicio R, García-González DL. A tentative characterization of white dry-cured hams from Teruel (Spain) by SPME-GC. Food Chem 2006;97:621-30.

11. Soto E, Hoz L, Ordóñez JA et al. Impact of feeding and rearing systems 
of Iberian pigs on volatile profile and sensory characteristics of drycured loin. Meat Sci 2008;79:666-76.

12. Ventanas S, Ventanas J, Estevéz M, Ruiz J. Analysis of volatile molecules in Iberian dry-cured loins as affected by genetic, feeding systems and ingredients. Eur Food Res Technol 2010;231:225-35.

13. Pastorelli G, Magni S, Rossi R et al. Influence of dietary fat, on fatty acid composition and sensory properties of dry-cured Parma ham. Meat Sci 2003;65:571-80.

14. Théron L, Tournayre P, Kondjoyan N, et al. Analysis of the volatile profile and identification of odour-active compounds in Bayonne ham. Meat Sci 2010;85:453-60.

15. ISO 13299.2:2003. Sensory analysis. Methodology. General guidance for establihing a sensory profile.

16. ISO 8586.2:1996. Sensory analysis. General guidance for the selection, training and monitoring of assessors part II - Experts.

17. Meilgaard M, Civille GV, Carr BT. Sensory evaluation techniques. 3rd ed. Boca Raton, NY: CRC Press; 1999.

18. García-Rey RM, Quiles-Zafra R, Luque de Castro MD. Relationships of genotype and slaughter time with the appearance and texture of dry-cured hams. Food Chem 2006;94:271-7.

19. Seong PN, Park KM, Kang GH, et al. The impact of ripening time on technological quality traits, chemical change and sensory characteristics of dry-cured loin. Asian-Australas J Anim Sci 2015;28:677-85.

20. Yim DG, Hong DI, Chung KY. Quality characteristics of dry-cured ham made from two different three-way crossbred pigs. Asian-Australas J Anim Sci 2016;29:257-62.

21. Fortin A, Robertson WM, Tong AKW. The eating quality of Canadian pork and its relationship with intramuscular fat. Meat Sci 2005;69:
297-305.

22. Martin D, Antequera T, Muriel E, Perez-Palacios T, Ruiz J. Volatile compounds of fresh and dry-cured loin as affected by dietary conjugated linoleic acid and monounsaturated fatty acids. Meat Sci 2009;81:549-56.

23. Yu AN, Sun BG, Tian DT, Qu WY. Analysis of volatile compounds in traditional smoke-cured bacon (CSCB) with different fiber coatings using SPME. Food Chem 2008;110:233-8.

24. Hierro E, De la Hoz L, Ordóñez JA. Headspace volatile compounds from salted and occasionally smoked dried meats (cecinas) as affected by animal species. Food Chem 2004;85:649-57.

25. Olivares A, Navarro JL, Flores M. Establishment of the contribution of volatile compounds to the aroma of fermented sausages at different stages of processing and storage. Food Chem 2009;115:1464-72.

26. García-González DL, Tena N, Aparicio-Ruiz R, Aparicio R. Sensor responses to fat food aroma: A comprehensive study of dry-cured ham typicality. Talanta 2014;120:342-8.

27. Maarse H, Visscher CA, Willemsens LC, Boelens MH. Volatile compounds in food. Qualitative and quantitative data. Vol. 1. Zeist, The Netherlands: Nutrition and Food Research Institute TNO; 1989.

28. Schmidt S, Berger RG. Aroma compounds in fermented sausages of different origins. LWT-Food Sci Technol 1998;31:559-67.

29. Sun W, Zhao Q, Zhao H, Zhao M, Yang B. Volatile compounds of Cantonese sausage released at different stages of processing and storage. Food Chem 2010;121:319-25.

30. Montel MC, Masson F, Talon R. Bacterial role in flavour development. Meat Sci 1998;49:111-23. 